\title{
Comparative Techno-Economic Analysis of Steam Explosion, Dilute Sulfuric Acid, Ammonia Fiber Explosion and Biological Pretreatments of Corn Stover
}

Nawa Raj Baral ${ }^{1,2}$, Ajay Shah ${ }^{1, *}$

${ }^{1}$ Department of Food, Agricultural and Biological Engineering, The Ohio State University, Wooster, Ohio, USA.

${ }^{2}$ Department of Mechanical Engineering, Institute of Engineering, Tribhuvan University, Kathmandu, Nepal.

* Corresponding Author: 110 FABE Building, 1680 Madison Avenue, Wooster, OH 44691, Phone: 330-263-3858, Email: shah.971@ osu.edu

\begin{abstract}
Pretreatment is required to destroy recalcitrant structure of lignocelluloses and then transform into fermentable sugars. This study assessed techno-economics of steam explosion, dilute sulfuric acid, ammonia fiber explosion and biological pretreatments, and identified bottlenecks and operational targets for process improvement. Techno-economic models of these pretreatment processes for a cellulosic biorefinery of 113.5 million liters butanol per year excluding fermentation and wastewater treatment sections were developed using a modeling softwareSuperPro Designer. Experimental data of the selected pretreatment processes based on corn stover were gathered from recent publications, and used for this analysis. Estimated sugar production costs $(\$ / \mathrm{kg})$ via steam explosion, dilute sulfuric acid, ammonia fiber explosion and biological methods were $0.43,0.42,0.65$ and 1.41 , respectively. The results suggest steam explosion and sulfuric acid pretreatment methods might be good alternatives at present state of
\end{abstract}


technology and other pretreatment methods require research and development efforts to be competitive with these pretreatment methods.

Keywords: corn stover; pretreatment; cellulosic biofuels; techno-economic analysis

\section{Introduction}

Butanol is a potential next generation liquid biofuel that can be produced from lignocellulosic biomass, including forest residues, agricultural residues and energy crops. Among these lignocelluloses, corn stover is a viable feedstock due to its immediate availability, high residue yield rate and ease of hydrolysis (DOE, 2011). Despite widespread effort in commercializing butanol production and availability of corn stover, lignin is a key problem in corn stover utilization as a feedstock. The lignin tightly binds cellulose and hemicellulose, and, at the same time cannot be used by the Clostridium species to produce butanol (Qureshi et al., 2008). Thus, lignocellulosic biomass requires pretreatment and enzymatic hydrolysis to transform the complex structure of cellulose and hemicellulose into simple sugars, which can be further transformed into biofuels.

Over the years, several pretreatment techniques are being investigated to disrupt the lignin matrix of a lignocellulosic biomass, which can be broadly divided into three categories: (1) physical; (2) chemical; and (3) biological (Jurgens et al., 2012; Kumar et al., 2009; Mood et al., 2013). Additionally, combinations of these pretreatment methods are also available. Generally, physical pretreatment reduces size of particle using mechanical energy and increases porosity of material without adding chemicals, such as acid or base (Cheng, 2010; Kumar et al., 2009). Some 
common examples of physical pretreatment methods are mechanical comminution, steam explosion, carbon dioxide explosion and hydrothermal pretreatment. In contrast to physical pretreatment, chemical pretreatment processes use chemical either acid or base for the pretreatment of lignocellulosic biomass at room temperature to elevated temperature for few minutes to several hours (Cheng, 2010). Sulfuric acid, hydrochloric acid, phosphoric acid, oxalic acid, tartaric acid, citric acid and acetic acid are used for pretreatment of lignocellulosic biomass. Additionally, some commonly used chemicals for alkaline pretreatment are sodium hydroxide, potassium hydroxide, lime, urea, ammonia, sodium carbonate, calcium hydroxide and methylamine. Apart from physical and chemical pretreatment methods, interests on biological pretreatment are also growing in recent years due to less pretreatment energy and simple reactor requirements as well as unnecessity of chemicals (Kumar et al., 2009; Wan and Li, 2010). Biological pretreatment uses bacteria, and brown, white and soft rot fungi to degrade lignocellulosic biomass (Wan and Li, 2010). Regardless of the method, the main goal of pretreatment is to destroy the structure of biomass and increase accessibility of enzyme by increasing porosity or surface area.

Among several physical, chemical and biological pretreatment methods, steam explosion, sulfuric acid, ammonia fiber explosion (AFEX) and biological with white rot fungi are commonly used pretreatment methods for lignocellulosic biomass (Jurgens et al., 2012; Kumar et al., 2009; Mood et al., 2013; Wan and Li, 2010). Overall comparison of some common pretreatment processes is available elsewhere (Jurgens et al., 2012; Kumar et al., 2009; Mood et al., 2013). All the above common pretreatment processes destroy structure of lignocellulosic biomass and partially convert cellulose and hemicelluloses into the fermentable sugars such as 
glucose, xylose, arabinose, galactose, and mannose. And then, a subsequent enzymatic hydrolysis process transforms remaining polymers into fermentable sugars. Depending upon the type of pretreatment and the process parameters, such as temperature and time, lignin is degraded into phenolics and the fermentable sugars mainly into hydroxymethylfurfural (HMF), furfural, acetic, levulinic, ferulic and glucuronic acids (Baral and Shah, 2014; Jurgens et al., 2012). The presence of these degradation products, commonly referred to as microbial inhibitors, results in low biofuel yield during fermentation. These inhibitory compounds either halt the fermentation process or slow down the reaction rates. Detailed discussions on microbial inhibitors formation from different pretreatment methods is found elsewhere (Baral and Shah, 2014).

While various potential pretreatment processes are available, they have different operating conditions and product yield rates. However, very few techno-economic studies, such as Baral and Shah, 2015; Eggeman and Elander, 2005; Kazi et al., 2010; Klein-Marcuschamer et al., 2011; Kumar and Murthy, 2011, are available for different pretreatment processes, such as sulfuric acid, hot water, ionic liquid, and ammonia fiber explosion. Apart from Baral and Shah, 2015, other studies did not consider impact of variation in process parameters, such as temperature and time, of a particular pretreatment. However, this study is also limited to ionic liquid pretreatment only. Recent review (Baral and Shah, 2014) found that the process parameters, specifically temperature and time, significantly impact unit sugar production and microbial inhibitors formations. Another recent techno-economic analysis of ionic liquid pretreatment process (Baral and Shah, 2015) found that pretreatment temperature and time not only significantly affect sugar production cost but also impact on quantity of process equipment requirement. A detail techno-economic analysis considering variations in process parameters is 
essential for sustainable butanol production. Additionally, all of the above mentioned technoeconomic studies are based on ethanol fermentation only. However, for the same quantity of biofuel production, ethanol and butanol fermentation require different levels of fermentable sugars requiring different levels of process equipment, feedstocks and other input materials.

In this regard, choice of a single pretreatment process for commercial butanol production is difficult at this stage. A thorough techno-economic analysis of each of these common pretreatment methods is required to identify the most cost effective pretreatment method for butanol production through $\mathrm{ABE}$ fermentation from corn stover feedstock. Thus, four common pretreatment methods, including steam explosion, dilute sulfuric acid, ammonia fiber explosion and biological pretreatment, are considered for techno-economic analysis in this study based on total sugars yield, microbial inhibitors formation, current research interests and general comparison of different pretreatment process available from literatures (Baral and Shah, 2015; Jurgens et al., 2012; Mood et al., 2013). This study also provides possible optimization techniques for each pretreatment method.

\section{Materials and Methods}

\subsection{Overview of modelling process}

Techno-economic process models for the selected pretreatment methods for a cellulosic biorefinery with a capacity of 113.5 million liters (i.e., 30 million gallons) butanol per year were developed using SuperPro Designer software v9.0009.2100 (Intelligen, 2014). Since the scope of the study was to compare different pretreatment technologies for fermentable sugars production, fermentation and wastewater treatment were excluded from the analysis. Annual capacity of the first generation cellulosic biorefineries is in the range of 75.7-133.5 million liters (20-30 million 
gallons) (Shah and Darr, 2016), thus, this biorefinery capacity of 113.5 million liters butanol per year was chosen as a model biorefinery. Figure 1 depicts the overview of process model with some major process equipment. The process model considered all unit operations required to transform the corn stover into biofuels. These unit operations were grouped into four major discrete units, namely corn stover preparation, pretreatment, detoxification and enzymatic hydrolysis.

\subsection{Distinct modelling unit and data sources}

Modelling assumptions were based on the data gathered from recently published studies on the selected pretreatment methods. After completion of the process flow diagram for all discrete units, necessary expressions and data required to accomplish material and energy balance, equipment size and purchasing price, maintenance and installation expenses for different operations were assigned to the models. Material and energy balance analysis results were further used to determine the equipment size and quantity, utilities and raw materials quantity, as well as other direct and indirect costs associated with capital and operating costs. The governing expressions to estimate purchasing price of equipment are available elsewhere (Intelligen, 2014; NREL, 2011, 2002).

\subsubsection{Corn stover preparation unit}

Based on the literature data on different $\mathrm{ABE}$ fermentation and recovery methods (Ezeji et al., 2003; Mariano et al., 2012; Qureshi et al., 2010), average butanol production from fermentable sugars is about $24 \mathrm{wt} \%$. Thus, about 386,924 metric ton (t) annual total sugars are required to produce 113.5 million liters butanol. In this study, corn stover was 
used as a model feedstock. Depending on type of pretreatment methods and their corn stover to sugar conversion rates (Figures 2 and 3), about 666,805-1,675,743 t dry corn stover was estimated (Figure 4) to be needed to produce the required amount of total fermentable sugars. Feedstock requirement is discussed in further detail in the results section. Moisture content in the feedstock was assumed to be $20 \mathrm{wt} \%$ based on previous study (NREL, 2011). With this moisture content, the estimated corn stover requirement was 834-2,095 thousand t/year. The feedstock preparation section was modeled to handle the required wet corn stover. The overall process flow diagrams of this section were same for all pretreatment methods although they handled different quantities of the required feedstock. Detail discussion about process flow diagram of this section can be found elsewhere (Baral and Shah, 2015), which mainly includes yard storage for corn stover bales, milling unit and storage for milled corn stover. Squeeze bale loader was considered to load corn stover bales from yard storage to milling unit. Additionally, belt or screw conveyers were used to convey the feedstock from one unit procedure to another.

\subsubsection{Pretreatment unit}

Milled corn stover was assumed to be fed into pretreatment reactor. Corn stover mainly consists of cellulose, hemicellulose and lignin. Table 1 summarizes the structural compositions of the corn stover used in this study. In addition to feedstock, water and chemicals were also assumed to be added before pretreatment depending on the type of the pretreatment process. Solid loading rate for pretreatment was maintained at $30 \mathrm{wt} \%$ for all pretreatment process (NREL, 2011). Remaining $70 \mathrm{wt} \%$ includes water and chemicals (if any). Steam explosion pretreatment requires water only. About $1 \mathrm{wt} \%$ of 
sulfuric acid was assigned for sulfuric acid pretreatment based on total slurry (NREL, 2011). For AFEX about $2 \mathrm{~g}$ ammonia/g dry matter was assigned (Bals et al., 2014) and the remaining concentration was adjusted by water (about $33 \mathrm{wt} \%$ based on total slurry). Finally, for biological pretreatment about $6 \mathrm{wt} \%$ white rot fungus inoculum was assigned based on total slurry (Wan and Li, 2010; Xu et al., 2010). The required chemical was assumed to be stored in a storage tank. Additionally, heat exchanger was used to recover waste heat from pretreated slurry except AFEX and biological pretreatment methods. Heat exchanger unit was not considered for AFEX and biological pretreatment methods due to low pretreatment temperature (Figure 2). As much as $80 \%$ of maximum possible heat was considered to be recovered through heat exchanger. Biomass slurry and chemicals were assumed to be conveyed through centrifugal pumps. Thus, irrespective of types of pretreatment process, this section basically includes pretreatment reactor, chemical storage unit and pumps.

As discussed earlier, all pretreatment processes destroy lignin barrier and partly transform cellulose and hemicellulose into fermentable sugars. Depending on types of pretreatment process, rate of conversion of cellulose, hemicellulose and lignin are different. Figure 2 summarizes conversions or losses during different pretreatment processes. Fungi consume cellulose and hemicellulose during degradation of lignin (Wan and Li, 2010), thus, the term 'losses' is used for the biological pretreatment. Conversions or losses of cellulose, hemicellulose and lignin are also dependent on severity factor (Figure 2). The severity factor is a relationship between pretreatment time and temperature. For instance, $180^{\circ} \mathrm{C}$ and 5 minutes are equivalent to severity factor of 3 . The relationship between severity factor and pretreatment conditions can be 
found elsewhere (Baral and Shah, 2014). Additionally, the severity factor also affects energy and cost. Thus, this study evaluated the impact of the severity factor and conversion rate on sugar production cost. Severity factor and conversion rate data were collected from recently published literature, and are summarized in Figure 2. Average conversion or losses rates were considered for all pretreatment methods used in this study during base case techno-economic analysis. Variations in conversion rates (Figure 2) found from the literatures were used for sensitivity analysis and process optimization.

Figure 2 (A1, A2 and A3) illustrates cellulose, hemicellulose and lignin conversion into glucose, xylose and soluble lignin, respectively during steam explosion pretreatment (Bondesson et al., 2013; Liu et al., 2013; Lloyd and Wyman, 2005; Varga et al., 2004; Zimbardi et al., 2007). This pretreatment method is usually carried out at a temperature of $160-260^{\circ} \mathrm{C}$ (saturation vapor pressure of 0.69-4.83 MPa) for 5-107 minutes. During steam explosion pretreatment at the severity factor of $3.64\left(200^{\circ} \mathrm{C}\right.$ and 5 minutes), in average, about $3.71 \mathrm{wt} \%$ of cellulose and 46.62 wt $\%$ of hemicellulose were found to be transformed into glucose and xylose, respectively (Figure 2-A1 and A2). Under the same severity factor, about $26.73 \mathrm{wt} \%$ of lignin was found to be converted into other chemicals (Figure 2-A3).

Cellulose, hemicellulose and lignin conversion rates into glucose, xylose and soluble lignin, respectively for dilute sulfuric acid pretreatment are included in Figure 2 (B1, B2 and B3) (Avci et al., 2013; Bondesson et al., 2013; Lau et al., 2009; Lloyd and Wyman, 2005; Qin et al., 2012; Shen and Wyman, 2011; Varga et al., 2004). Most of the experimental studies on the sulfuric acid pretreatment are conducted at $130-200{ }^{\circ} \mathrm{C}$ for $15-60$ min with the sulfuric acid 
concentration of $0.5-2 \mathrm{wt} \%$ (Figure 2-B). As much as $1.1 \mathrm{wt} \%$ sulfuric acid can be handled by the process equipment used in this study (NREL, 2011). Higher concentration of acid impacts on the equipment cost as corrosion resistive material is required due to corrosive nature of acid. Thus, $1 \mathrm{wt} \%$ sulfuric acid was considered in this study for base case analysis, which is closely represented by the best fit curves (Figure 2-B1, B2 and B3). During dilute sulfuric acid pretreatment at the severity factor of $3.07\left(160^{\circ} \mathrm{C}\right.$ and 20 minutes), in average, about $10.7 \mathrm{wt} \%$ of cellulose and $75.88 \mathrm{wt} \%$ of hemicellulose and $17.01 \mathrm{wt} \%$ of lignin were found to be transformed into glucose and xylose, and soluble lignin, respectively (Figure 2$\mathrm{B} 1, \mathrm{~B} 2$ and $\mathrm{B} 3)$.

Figure 2 (C) illustrates cellulose, hemicellulose and lignin conversion into glucose, xylose and soluble lignin, respectively for AFEX pretreatment (Bals et al., 2014; Lau et al., 2009; Li et al., 2011; Uppugundla et al., 2014; Wyman et al., 2005). This pretreatment process is usually conducted at $40-150^{\circ} \mathrm{C}$ for retention duration of 5 minutes to 60 days using the ammonia concentration of 1- $2.5 \mathrm{~g}$ ammonia/g dry biomass (Figure 2-C). Longer retention time is required for the lower pretreatment temperature. AFEX pretreatment usually destroys lignin barrier, thus, most of the literatures have not reported cellulose and hemicellulose conversions during this pretreatment. Additionally, previous techno-economic studies on ethanol fermentation considering AFEX pretreatment (Eggeman and Elander, 2005; Kazi et al., 2010) did not consider cellulose, hemicellulose and lignin conversions during pretreatment. Thus this study also assumed $100 \%$ recovery of cellulose, hemicellulose and lignin after AFEX pretreatment at an average severity factor of $1.5\left(120^{\circ} \mathrm{C}\right.$ and 8 minutes $)$ although this process destroys lignin barrier and facilitate successive enzymatic hydrolysis process. 
Figure 2 (D) illustrates cellulose, hemicellulose and lignin losses during biological pretreatment (Gao et al., 2012; Liu et al., 2014; Ma and Ruan, 2015; Song et al., 2013; Wan and Li, 2010; Wang et al., 2013; Xu et al., 2010). This pretreatment process is usually conducted at $28^{\circ} \mathrm{C}$ for 18 days to several weeks (Figure 2-D). During fungal based biological pretreatment considered in this study, in average, about $18.54 \mathrm{wt} \%$ of cellulose and $60.59 \mathrm{wt} \%$ of hemicellulose and $38.66 \mathrm{wt} \%$ of lignin were found to be degraded at the severity factor of $2.4\left(28^{\circ} \mathrm{C}\right.$ and 23 days) (Figure 2-D). Current assumption is that about $30 \mathrm{wt} \%$ lignin degradation may be sufficient for effective enzymatic hydrolysis (Cheng, 2010). Thus, conditions required for around $30 \mathrm{wt} \%$ lignin degradation and optimum glucose yield (Figure 3-D) was assumed for base case analysis in this study.

In addition to cellulose, hemicellulose and lignin, acetyl groups in the hemicellulose are liberated as acetic acid. The equations governing chemical reactions of these conversion processes can be found elsewhere (NREL, 2011, 2002). Apart from acetic acid and fermentable sugars, sugar degradation products, such as furfural and 5-hydroxymethyl furfural (HMF), are also formed during dilute acid and steam explosion pretreatment. These products cause inhibitory effects during the fermentation process and their formation specifically depends on the severity factor (Baral and Shah, 2014). Thus, the slurry after these pretreatement processes is fed to the detoxification unit. On the other hand, pretreated slurry after ammonia fiber explosion and biological pretreatments were assumed to be fed directly into the enzymatic hydrolysis unit without detoxification. 


\subsubsection{Detoxification unit}

While process inhibitors are not reported for ammonia fiber explosion and biological pretreatments, these inhibitors are formed during dilute acid and steam explosion pretreatments. Thus, the pretreated slurry after dilute sulfuric acid and steam explosion pretreatment were assumed to be fed to overliming reactor, where 5\% excess ammonia was assumed to be added after neutralization to reduce process inhibitors. The excess ammonia is neutralized with addition of sulfuric acid in the following neutralization reactor. All the input chemicals and corn stover slurry were assumed to be transferred through centrifugal pump. Material and energy balance were conducted by assigning standard chemical equations with input and process chemicals, as suggested by NREL (2011). After detoxification, the detoxified slurry was assumed to be fed into enzymatic hydrolysis reactor.

\subsubsection{Enzymatic hydrolysis unit}

The disruption of structure of biomass increases assessable surface area for enzyme, which can transform most of the remaining cellulose and hemicellulose into fermentable sugars during the enzymatic hydrolysis process. The detoxified slurries for steam explosion and sulfuric acid pretreatments or pretreated corn stover for the other pretreatment methods were assumed to be hydrolysed with enzyme to transform pretreated corn stover into fermentable sugars. These fermentable sugars mainly glucose and xylose are metabolized by microbes to produce biofuels. For this conversion, cellulase enzyme was assigned at a loading rate of $20 \mathrm{mg}$ protein per $\mathrm{g}$ cellulose (NREL, 2011). The total solid loading rate was maintained at $20 \mathrm{wt} \%$ with addition of water (NREL, 2011). Following this, all the mixture was assumed to be fed to hydrolysis reactor 
using centrifugal pump. Thus, this section mainly includes enzyme storage tank, mixing unit, pump and hydrolysis reactor.

Hydrolysis time of 72 hours was assumed for this study irrespective of pretreatment methods used because most of the data used in this study are based on $72 \mathrm{~h}$ of enzymatic hydrolysis. The experimental data on cellulose and hemicellulose conversions during enzymatic hydrolysis for each pretreatment process were collected from recently published literatures as mentioned in the pretreatment unit, and are summarized in Figure 3. For base case analysis, average conversion rates were assumed based on the severity factor used for pretreatment process. During enzymatic hydrolysis, about $67.92 \mathrm{wt} \%$ of cellulose and $58.45 \mathrm{wt} \%$ of hemicellulose conversion rates were found for steam explosion pretreated corn stover at an average severity factor of 3.64. These conversion rates are based on remaining cellulose and hemicellulose after the pretreatment process. For sulfuric acid pretreated corn stover at an average severity factor of 3.07, about 69.51 wt $\%$ of remaining cellulose and $64.99 \mathrm{wt} \%$ of remaining hemicellulose conversions were found during enzymatic hydrolysis. AFEX pretreated corn stover has comparatively higher cellulose and hemicellulose conversion rates of 90.32 and $84.01 \mathrm{wt} \%$ during enzymatic hydrolysis when AFEX pretreated corn stover at a severity factor of 1.5 is used. Finally, about $62.03 \mathrm{wt} \%$ of cellulose and $36.22 \mathrm{wt} \%$ of hemicellulose conversions were found during enzymatic hydrolysis after biological pretreatment at an average severity factor of 2.4. Variations in conversion rates during enzymatic hydrolysis (Figure 3) were used for sensitivity analysis and process optimization. 


\subsection{Analyses}

\subsubsection{Process economics}

Capital and operating cost parameters used to estimate capital and sugar production costs were gathered from previous studies (Brown, 2003; NREL, 2011, 2002; Ulrich, 1984). The pretreatment facility for butanol production was assumed to be operated 330 days per year and 24 h per day (Klein-Marcuschamer et al., 2011; NREL, 2011; OleskowiczPopiel et al., 2014)). Service life of the pretreatment facility was assumed to be 30 years. Purchasing price of equipment was obtained from previous studies (DOE/NETL, 2002; NREL, 2011, 2002). While these previous studies (NREL, 2011, 2002) were based on sulfuric acid pretreatment, price of process equipment and accessories required for other pretreatment processes was approximated using closely relevant equipment and accessories (NREL, 2011, 2002). After completion of mass and energy balance analysis of all process equipment, their sizes and quantities were determined. Based on the estimated equipment sizes obtained from the process model and equipment sizes and purchasing price used in the previous reports and studies (DOE/NETL, 2002; Kumar and Murthy, 2011; NREL, 2011, 2002), a reasonable equipment prices were obtained. Then, the estimated equipment price of each equipment was further adjusted to the analysis year (2015). Apart from equipment purchase price, an installation factor for different process equipment used in this study was assigned based on previous literatures (Brown, 2003; Ulrich, 1984) and modelling software (Intelligen, 2014) used in this study. Then, the fixed costs that are associated with a process, i.e., total capital investment (TCI), was calculated as the sum of following cost items: direct fixed capital (DFC), working capital, and startup cost. The DFC includes direct cost (equipment purchase, installation, piping, 
instrumentation, electrical, insulation, buildings, yard improvement, and auxiliary facilities cost) and the associated indirect costs (construction, engineering, contractor's fee, and contingency). The working capital is the tied-up funds required to operate the biorefinery, and accounts for raw materials, consumables, labor and utilities. Similarly, the start-up cost is a one-time investment to prepare a new plant for operation (Intelligen, 2014).

Apart from capital investment, annual operation cost was estimated as the sum of the facility-dependent cost, raw materials, labor-dependent cost, heating/cooling utilities and electricity. The facility dependent cost is the cost related to the use of a facility, which was estimated as the sum of the costs associated with equipment maintenance (10\% of purchase cost), depreciation of the fixed capital cost, and miscellaneous costs, such as insurance (1\% of DFC), local (property) taxes (2\% DFC) and factory overhead expenses (5\% of DFC) (Intelligen, 2014). Apart from the facility dependent cost, material costs, such as price of feedstock and other input materials, were gathered from previous studies. The average price used to deliver the corn stover to the biorefinery gate $(\$ / \mathrm{kg})$ was estimated to be 0.11 excluding overheads (Shah and Darr, 2016). Sulfuric acid, ammonia and enzyme prices at the biorefinery gate $(\$ / \mathrm{kg})(\mathrm{NREL}, 2015)$ of $0.11,0.55$ and 0.24 , respectively, were used in this study. Based on chemicals requirement to prepare inoculum (Keller et al., 2003), cost (\$/kg) of white rot fungi inoculum was estimated to be $\$ 0.02 / \mathrm{kg}$. Additionally, price of water $(\$ / \mathrm{kg})$ was considered to be 0.0002 (NREL, 2011). The labor hour required for each unit operations were gathered from literatures (Brown, 2003; DOE/NETL, 2002; Intelligen, 2014). Labor rate (\$/h) was assumed to be $\$ 69 / \mathrm{h}$ (Intelligen, 2014) including basic rate, benefits, supervision, operating 
supplies and administration. Steam (4.1MPa), cooling water and chilled water were assumed for heating and cooling agents and their costs $(\$ / t)$ were assumed to be $12,0.4,0.05$, respectively (Intelligen, 2014). Finally, purchasing price of electricity was assumed to be $\$ 0.07 / \mathrm{kWh}$ (EIA, 2014) for industrial use.

\subsubsection{Sensitivity analysis and optimization}

Previous section discussed economic analysis of different pretreatment processes based on the average values of technical and economic parameters including inputs, conversion rates and capital cost. Variation in the process technical and economic parameters could change sugar production cost. For instance, glucose and xylose conversion rates were found to be varied with severity factor (Figures 2 and 3). Even for the same severity factor these conversion rates were different. Sugar production cost (Figure 5) is dependent on several input parameters, such as feedstock cost, heat recovery, glucose and xylose yield, solid loading rate, plant size and moisture content.

These input parameters generally have different level of impact on the sugar production cost. Thus, a sensitivity analysis was conducted to determine the effects of uncertainties in the inputs on the sugar production cost. This analysis examined influence of different input parameters on the output by changing their values by $\pm 20 \%$. Apart from the sensitivity analysis, optimum sugar production cost was estimated using optimistic data for the most sensitive input parameters, which is discussed in the optimization section. 


\section{Results and discussion}

\subsection{Material and energy balance}

Corn stover feedstock requirements estimated for 113.5 million liters annual butanol production with steam explosion, sulfuric acid, AFEX and biological pretreatment were 818,$826 ; 746,797 ; 666,805 ; 1,675,743$ dry t/year, respectively. Figure 4 summarizes materials and energy required to produce $1 \mathrm{t}$ total sugars including glucose and xylose. AFEX pretreatment was found to require the lowest amount of feedstock. This is due to assuming $100 \%$ recovery of cellulose and hemicellulose during AFEX pretreatment (Figure 2-C) and about 1.3 fold higher average cellulose and hemicellulose conversion rate than sulfuric acid pretreatment during enzymatic hydrolysis (Figure 3-C). On the other hand, biological pretreatment was found to require about 2.2 fold higher feedstock than the sulfuric acid pretreatment due to degradation of cellulose and hemicellulose during pretreatment (Figure 2-D) and about 1.2 and 1.8 folds lower cellulose and hemicellulose conversion rates, respectively, during enzymatic hydrolysis (Figure 3-D). About 1.1 fold higher feedstock requirement for steam explosion pretreatment is mainly due to 1.1 fold lower total sugar yield than sulfuric acid pretreatment (Figures 2 and 3-A).

In addition to corn stover feedstock, water was found to be another main input material. Similar to feedstock, the highest water was found to be required for biological pretreatment followed by steam explosion, sulfuric acid and AFEX pretreatment (Figure 4). The biological pretreatment process was found to require about $19.3 \mathrm{t}$ water/t sugar produced excluding $20 \mathrm{wt} \%$ moisture of the feedstock. About $62 \%$ of this total water was found to be required for pretreatment to maintain the required water content of $75 \mathrm{wt} \%$ 
(Wan and Li, 2010; Xu et al., 2010). Additionally, about 4\% of the total water was found to be required for washing process after pretreatment to remove fungi contamination. Previous study (Sindhu et al., 2015) reported that ligninolytic enzyme contamination has a negative effect on enzymatic hydrolysis using cellulase, thus the water washing step was considered after biological pretreatment. Remaining $34 \%$ water was required to maintain $20 \mathrm{wt} \%$ solid loading ratio during enzymatic hydrolysis. AFEX was found to require the lowest amount of water of $2.9 \mathrm{t} / \mathrm{t}$ total sugars produced excluding feedstock moisture. About $74 \%$ of the total required water for the AFEX pretreatment was found to be required for pretreatment process and remaining $26 \%$ water was found to be required during enzymatic hydrolysis process. Sulfuric acid and steam explosion were found to require 4.02 and $4.40 \mathrm{t}$ water/t total sugar produced during pretreatment process only as whole slurry was assumed to be fed to enzymatic hydrolysis reactor after detoxification.

Apart from feedstock and water, sulfuric acid pretreatment required about $75 \mathrm{~kg}$ sulfuric acid/t total sugars produced. About $95 \%$ of the total sulfuric acid was found to be required for pretreatment and remaining $5 \%$ was required to neutralize excess ammonia after detoxification process. Ammonia was used to reduce inhibitory compounds formed during pretreatment (NREL, 2011), which was required about $60 \mathrm{~kg} / \mathrm{t}$ total sugars produced through sulfuric acid pretreatment. In addition to the sulfuric acid pretreatment, steam explosion pretreatment was also found to require about $23 \mathrm{~kg}$ ammonia and $2 \mathrm{~kg}$ sulfuric acid per metric ton total sugars production for detoxification and neutralizing excess ammonia. AFEX pretreatment was found to require about $3.5 \mathrm{t}$ ammonia/t total sugars produced. About $98 \mathrm{wt} \%$ of ammonia was assumed to be recycled after 
pretreatment, which reduces additional required ammonia for the pretreatment process, while fulfilling the constant overall requirement. In contrast to chemical requirements for the pretreatment processes discussed so far, biological pretreatment was found to require about $1.1 \mathrm{t}$ inoculum/t total sugars produced during pretreatment.

Finally, enzyme mixtures (kg/t total sugars produced) of 319, 270, 269 and 541 were found to be required to transform cellulose and hemicellulose into fermentable sugars for steam explosion, sulfuric acid, AFEX and biological pretreatment processes, respectively. The enzyme mixture contains about $95 \mathrm{wt} \%$ of water (NREL, 2011). Figure 4 summarizes all input materials, products and wastes.

Figure 4 also summarizes energy flow and net external energy required to transform corn stover feedstock into fermentable sugars. The energy flow in a particular stream includes enthalpy, which is dependent on mass and temperature of the materials flowing through the stream. On the other hand, electrical energy and energy associated with process steam and cooling water were considered for the external energy. Apart from biological pretreatment process, for all other pretreatment processes, pretreatment section was found to be more energy intensive followed by enzymatic hydrolysis unit, corn stover preparation unit and detoxification unit (If any) (Figure 4). The biological pretreatment process was found to require about 12 fold less energy for pretreatment process mainly due to the lower pretreatment temperature of $28^{\circ} \mathrm{C}$ when compared to pretreatment temperature of $160^{\circ} \mathrm{C}$ considered for sulfuric acid pretreatment. Biological pretreatment was also found to require the lower total external energy of about $461 \mathrm{kWh}$ to produce $1 \mathrm{t}$ 
total sugars among the pretreatment processes considered in this study. During the biological pretreatment process about $57 \%$ of the total external energy was found to be required for enzymatic hydrolysis unit followed by pretreatment process of $33 \%$ and the remaining $10 \%$ was found to be required for corn stover preparation unit.

On the other hand, AFEX pretreatment was found to require the highest external energy of $9558 \mathrm{kWh}$ to produce $1 \mathrm{t}$ total sugars. About $98 \%$ of this energy was found to be required for pretreatment and recovery of ammonia. This higher energy requirement may be due to absence of heat recovery unit. The heat recovery unit was not considered due to requirement of rapid release of pressure or explosion reducing temperature, lower temperature difference of about $10^{\circ} \mathrm{C}$ between input and output streams, and exploded streams mainly contains biomass and ammonia. Waste heat recovery can reduce the external energy requirement; however, it can also increase facility dependent cost (Baral and Shah, 2015). Thus, heat recovery may not be feasible for the AFEX pretreatment considering waste heat within the pretreatment section; however, waste heat from other sections of biofuel production system, for instance, stillage utilization unit, could be used to reduce the external energy requirement.

While steam explosion pretreatment also requires rapid release of pressure or explosion after pretreatment similar to the AFEX pretreatment, heat from exploded stream was recovered due to the higher temperature difference of about $91^{\circ} \mathrm{C}$ between input and output streams, and exploded streams mainly contains water. Considering heat recovery, the steam explosion pretreatment required $1666 \mathrm{kWh}$ external energy to produce $1 \mathrm{t}$ total 
sugars. About $94 \%$ of this energy was found to be required for pretreatment section followed by $3 \%$ for enzymatic hydrolysis unit and remaining $2 \%$ for corn stover preparation unit. The waste heat recovery was also considered for sulfuric acid pretreatment process, which required about $2102 \mathrm{kWh}$ additional external energy to produce $1 \mathrm{t}$ total sugars. Majority of this energy, about $91 \%$, was found to be required for pretreatment unit followed by $7 \%$ for enzymatic hydrolysis unit and remaining $2 \%$ for corn stover preparation unit. About $80 \%$ of waste heat was assumed to be recovered during steam explosion and sulfuric acid pretreatment process (Baral and Shah, 2015).

About 2.8 fold less external energy was found to be required for enzymatic hydrolysis unit of steam explosion pretreatment methods when compared to sulfuric acid pretreatment process mainly due to $33 \%$ higher temperature of input pretreated slurry in the enzymatic hydrolysis reactor resulting less utilities requirement. The higher pretreatment temperature of $200^{\circ} \mathrm{C}$ for steam explosion pretreatment when compared to pretreatment temperature of $160^{\circ} \mathrm{C}$ of sulfuric acid pretreatment and assuming similar detoxification unit resulted in the higher temperature of pretreated slurry. Overall, pretreatment and fermentation reactors, hammer mill and materials handling pumps were major energy contributor for all pretreatment process. Additionally, flash condenser was another major energy contributor for AFEX pretreatment process, which was used to release the pressure and recovery of ammonia after pretreatment. 


\subsection{Capital investment, operating and unit sugar production cost}

Table 2 illustrates total capital requirement and its components to produce sugar from corn stover for 113.5 million liters/year (i.e., 30 million gallons/year) butanol.

Comparatively, the lower capital investment was found for AFEX pretreatment because it has high overall sugar conversion rate from corn stover (Figures 2 and 3) and does not require detoxification unit. Similar result was found in previous study (Baral and Shah, 2015) when feedstock requirement varies to produce the particular amount of fermentable sugars.

Although biological pretreatment process does not require detoxification unit, about 12 fold more capital investment is required when compared to other pretreatment processes. One obvious reason is that biological pretreatment requires about 2 fold more feedstock to produce the same amount of fermentable sugars than other pretreatment processes requiring different capacity or quantity of process equipment. Another main reason is that biological pretreatment requires large number of pretreatment reactors mainly due to long pretreatment time (23 days considered in this study). Biological pretreatment reactor assumed in this study is equivalent to anaerobic digester considered in previous study (NREL, 2011) as biological pretreatment reactor may not require sophisticated and decent strength material like sulfuric acid pretreatment. Unit purchasing price of the biological

pretreatment reactor considered in this study $\left(\$ 343 / \mathrm{m}^{3}\right)(\mathrm{NREL}, 2011)$ was about 389 times less than unit cost of sulfuric acid pretreatment reactor considered in this study. The lower unit price of the biological reactor is mainly due to both the larger reactor size (about 207 times more than the reactor size used for sulfuric acid pretreatment) and the 
less corrosive material required. Thus, rather than price of the reactor, the higher quantity of biological pretreatment reactors leads to high capital investment. This result reflects biological pretreatment in any kind of reactor or even in a simple storage tank may not be feasible. Biological pretreatment at feedstock storage unit may reduce the capital investment, although previous study (Sindhu et al., 2015) reported that a good venting and controlling system is required for biological pretreatment reactor to control important culture parameters, such as $\mathrm{pH}$ and temperature. Thus, further researches are required to get benefits of biological pretreatment process for large scale applications.

Apart from biological pretreatment, other pretreatment processes required almost similar level of capital investment. Regardless of type of pretreatment processes, purchasing price of hammer mill, feedstock storage bin, and pretreatment and hydrolysis reactors were the major contributors to the total fixed capital investment.

Table 3 summarizes the total annual operating cost required for different pretreatment methods. Corn stover feedstock was found to be a major contributor to operating cost accounting for 53.2 and $49.5 \%$ of the total annual operating costs for steam explosion and sulfuric acid pretreatments, respectively, followed by other chemicals costs including sulfuric acid and ammonia, facility dependent cost, utilities and labor cost. The facility dependent cost includes depreciation, maintenance and insurance. On the other hand, utilities and facility-dependent cost contributed to about $53 \%$ of the total annual operating cost for AFEX and biological pretreatment methods, respectively. The higher utilities cost for AFEX pretreatment is due to requirement of a flash to release pressure rapidly, 
recycling ammonia and absence of heat recovery as discussed earlier. Obviously, facility dependent cost is the major contributor for biological pretreatment due to high requirement of capital investment. Additionally, corn stover feedstock was another major contributor to annual operating cost for both AFEX and biological pretreatment methods contributing to 29.3 and $33.9 \%$ of the total operating cost, respectively. In contrast to other pretreatment processes, biological pretreatment process was found to require the lower utilities due to low pretreatment temperature of $28^{\circ} \mathrm{C}$ considered in this study.

Figure 5 depicts sugar production cost for different pretreatment methods under different sections. The estimated sugar production costs $(\$ / \mathrm{kg})$ were $0.43,0.42,0.65$ and 1.41 for steam explosion, sulfuric acid, AFEX and biological pretreatment, respectively. While feedstock preparation section was major contributor to sugar production cost for steam explosion and sulfuric acid pretreatment processes, the major contributor to sugar production cost for AFEX and biological pretreatment processes was pretreatment section. Feedstock preparation section accounted for 59.5 and $55.4 \%$ of total sugar production cost for steam explosion and sulfuric acid pretreatment processes, respectively, where corn stover feedstock was major cost contributor (Table 3). On the other hand, pretreatment unit accounted for 54.2 and $51.3 \%$ of total sugar production cost for AFEX and biological pretreatments, where utilities and facility dependent cost were major cost contributors, respectively (Table 3). Enzymatic hydrolysis unit was second major contributor for steam explosion and sulfuric acid pretreatment, which accounts for 23.6 and $21.5 \%$ of total sugar production cost. Major cost contributor to enzymatic hydrolysis unit was enzyme, which contributed about 71 and $69 \%$ of total hydrolysis cost 
for steam explosion and sulfuric acid pretreatment, respectively. In contrast, utilities were major cost contributor for pretreatment process, which accounted about $52 \%$ of total pretreatment cost for steam explosion and sulfuric acid pretreatment. Further, detoxification unit accounts about $1 \%$ of total sugar production cost for steam explosion and sulfuric acid pretreatment.

Apart from pretreatment, feedstock preparation was second major cost contributor to AFEX and biological pretreatment, which accounted for 32.6 and 36.6 of total sugar production cost, respectively, where major cost contributor was corn stover feedstock. Following this, enzymatic hydrolysis unit accounted about 13.3 and $12.1 \%$ of total sugar production cost for AFEX and biological pretreatments, respectively, where enzyme itself accounted for 71 and $73 \%$ of total hydrolysis cost, respectively.

\subsection{Comparison of sugar production cost to previous studies}

While several techno-economic studies on ethanol fermentation are available (Table 4), very few previous studies (NREL, 2011, 2002) reported sugar production cost. Additionally, most of those studies were derived from NREL (2002) and (2011), specifically focusing on dilute sulfuric acid pretreatment and various lignocellulosic biomass feedstocks including corn stover. Thus, apart from NREL (2002) and (2011), sugar production cost summarized in Table 4 was estimated considering ethanol production cost and feedstock to ethanol and sugar conversion rates reported on those studies. Additionally, to estimate the sugar production cost, cost contribution by feedstock preparation and pretreatment sections was assumed to be about $50 \%$ of total ethanol production cost (NREL, 2011). Contribution of AFEX pretreatment cost in total ethanol 
production cost may be higher than Contribution of sulfuric acid pretreatment cost of about $50 \%$ due to ammonia recovery; thus, sugar production cost estimated from previous studies for AFEX pretreatment for comparison with those in this study might be low.

Irrespective of differences among previous techno-economic studies and this study, a good correlation $\left(\mathrm{R}^{2}=0.86\right)$ between sugar production cost and feedstock price was found for sulfuric acid pretreatment. Previous study (Kumar and Murthy, 2011) also reported that ethanol production price is mainly dependent on feedstock price. Similar conclusion can be made for other pretreatment method as well. In addition to feedstock cost, differences in sugar production cost (Table 4) can be attributed to the differences in solid loading rate of 20-30 wt $\%$, prices $(\$ / \mathrm{kg}$ ) of different chemicals: sulfuric acid- 0.0350.08 , ammonia- $0.09-0.44$, and enzyme price ( $\$ / \mathrm{kg}$ protein) of 4-5. Price of enzyme and other process chemicals were $20-35 \%$ higher than previous studies. Another possible reason of the higher sugar production cost found in this study is may be due to difference in feedstock to sugar conversion rates and analysis year. Additionally, the larger amount of feedstock for butanol production when compared to the same quantity of ethanol requires the higher facility and labor dependent costs resulted in the higher sugar production cost in this study. The sugar production cost obtained in this study could be further reduced, which is discussed in the optimization section. Additionally, choice of a particular pretreatment process for biofuel production is dependent on quality of fermentable sugar, biofuel yield during fermentation and ease of wastewater treatment process, which requires further research and analysis. 


\subsection{Sensitivity analysis}

Figure 6 summarizes sensitivity of the sugar production cost under different pretreatment methods. Feedstock cost was found to be the most sensitive input parameter for steam explosion and sulfuric acid pretreatment. This is obvious because sugar production cost of these pretreatment methods was dominated by feedstock cost (Table 3). Previous study (Kumar and Murthy, 2011) also reported feedstock cost as the most sensitive parameter to ethanol production cost under these two pretreatment methods. On the other hand, solid loading rate was found to be most sensitive parameter for AFEX pretreatment. This may be because solid loading rate determines the amount of ammonia during AFEX pretreatment, which ultimately influences cost contribution from ammonia and utilities during pretreatment and recovery of ammonia.

Glucose yield during hydrolysis was found to be most sensitive parameter for biological pretreatment method, while this was found to be second most sensitive parameter for other pretreatment methods. This may be due to glucose yield not only determines quantity of feedstock requirement, but also total output sugar. The quantity of feedstock requirement determines pretreatment reactor size and quantity, which is specifically important for biological pretreatment process as majority of sugar production cost is dependent on facility dependent cost (Table 3). Solid loading rate was another sensitive parameter for biological pretreatment, which also determines quantity of water requirement and then, overall feedstock to be processed affecting pretreatment reactors requirement. 
Heat recovery was found to be third most sensitive parameter for steam explosion and sulfuric acid pretreatment methods. Heat recovery is a good trade-off between utilities requirement and facility dependent cost (Baral and Shah, 2015). Xylose yield during enzymatic hydrolysis was found third influencing parameter for AFEX pretreatment, which impacts similar to glucose yield during sugar production. The third sensitive parameter for biological pretreatment was severity factor, which was the fourth most sensitive parameter for other pretreatment methods. Severity factor may have cumulative effect on sugar production cost because glucose and xylose yield during pretreatment and enzymatic hydrolysis, and pretreatment reactors and utilities requirement are dependent on the severity factor. Thus, this is even more important for biological pretreatment due to a long pretreatment time. Previous study (Baral and Shah, 2015) also found severity factor as an influencing input parameter for sugar production cost during ionic liquid pretreatment.

Apart from glucan and xylan losses during biological pretreatment, and glucose and xylose yields for other pretreatment, enzyme cost was found as a sensitive parameter. Previous studies (Kazi et al., 2010; NREL, 2011) also found enzyme cost as a sensitive input parameter on ethanol production cost under similar pretreatment methods. Other influencing parameters for steam explosion, sulfuric acid, AFEX and biological pretreatment are illustrated in figure 6 . Those parameters either impact corn stover feedstock and other input chemicals requirement or facility and utilities requirement.

\subsection{Optimistic unit sugar production cost}


The sugar production cost obtained from base case analysis as discussed earlier could be reduced through the selection of an optimistic value of each of the most sensitive input parameter under each pretreatment process. Feedstock cost is one of the key parameters, which determines sugar production cost. Previous studies (DOE, 2011; NREL, 2011; Shah and Darr, 2016) reported that optimization in corn stover supply logistics and selection of the best location of the biorefinery could reduce feedstock cost. Under such conditions corn stover could be available at an optimistic price $(\$ / \mathrm{kg})$ of 0.064 , which was also used in recent techno-economic studies on biofuels production systems (NREL, 2011; Tao et al., 2014). Thus, corn stover feedstock cost $(\$ / \mathrm{kg})$ of 0.064 was considered as an optimistic feedstock cost in this study. Apart from feedstock, glucose and xylose yields or losses during pretreatment and enzymatic hydrolysis were assumed to be an average maximum possible value obtained from recent studies under each pretreatment method (Figures 2 and 3).

Apart from feedstock and conversion rates, a proper selection of severity factor could further reduce sugar production cost by reducing utilities and quantity of reactors requirement. Optimum severity factors for each pretreatment process were selected based on total sugar yield obtained from experimental studies (Figures 2 and 3). Solid loading rate was another sensitive input parameter. An optimistic solid loading ratio of $40 \mathrm{wt} \%$ was assumed for pretreatment reactor, while solid loading rate for enzymatic hydrolysis was maintained at $20 \mathrm{wt} \%$. The optimistic solid loading rate considered in this study is very optimistic when compared to $\sim 10 \mathrm{wt} \%$ solid loading ratio considered in experimental studies (Figures 2 and 3). However, previous techno-economic studies (Kazi 
et al., 2010; NREL, 2011) assumed solid loading ratio of 30 and 48 wt $\%$ for sulfuric acid and AFEX pretreatment methods, respectively, thus this study considered the optimistic solid loading ratio of $40 \mathrm{wt} \%$ for all pretreatment processes.

Enzyme loading and cost were found to be other key contributors to sugar production cost. Overall enzyme cost can be reduced by optimizing both enzyme loading rate and cost (NREL, 2011). However, in this study, enzyme loading rate was maintained at 20 $\mathrm{mg}$ protein $/ \mathrm{g}$ cellulose and enzyme cost was assumed to be reduced to $\$ 0.12 / \mathrm{kg}$ considering onsite enzyme production could reduce the cost. The enzyme solution considered in this study contained about $4.5 \mathrm{wt} \%$ protein (NREL, 2011). An optimistic value of heat recovery was assumed to be $90 \%$ (Baral and Shah, 2015) for steam explosion and sulfuric acid pretreatment methods, which is a key contributor to reduce utilities requirement specifically for pretreatment reactor. Thus, importance of heat recovery increases with increase in pretreatment temperature. Furthermore, optimistic value of moisture content and plant size were assumed to be $12 \%$ and 189 million liters per year (50 million gallons per year), respectively.

Considering the most optimistic values of several input parameters collectively reduced the sugar production cost $(\$ / \mathrm{kg})$ to $0.212,0.208,0.305$ and 0.590 under steam explosion, sulfuric acid, AFEX and biological pretreatment methods, respectively. Reduction in feedstock and enzyme cost, and increase in glucose yield during enzymatic hydrolysis were some key parameters reducing sugar production cost under steam explosion and sulfuric acid pretreatment methods. For AFEX pretreatment, high solid loading rate and 
low feedstock cost were found to be key contributors reducing sugar production cost. Finally, Optimistic sugar production cost under biological pretreatment was found to be dependent on several parameters including glucose and xylose yield during enzymatic hydrolysis, solid loading rate, severity factor (specifically pretreatment duration), feedstock cost, and glucan and xylan loss during pretreatment.

\section{Conclusion}

At the current state of the pretreatment technologies, steam explosion, sulfuric acid and AFEX pretreatments could be the cost competitive options due to their close sugar production cost $(\$ / \mathrm{kg})$ of $0.43,0.42$ and 0.65 , respectively. However, the sugar production cost $(\$ / \mathrm{kg})$ through biological pretreatment is 1.41 and higher than the others. Optimization of the most sensitive parameters, including feedstock cost, feedstock to sugar conversion rates, solid loading rate and enzyme cost, could reduce the overall sugar production cost. These could be achieved through process optimization and intensification, which require further research.

\section{Notes}

Some technical and economic results are included in the supplementary document including step by step reduction in sugar production cost considering the most optimistic values of several input parameter, which is available from the website of the journal.

\section{Acknowledgement}


This work was partly supported by funding from the USDA NIFA Hatch project 1005665, Ohio Agricultural Research and Development Center (OARDC) SEEDS grant (OHOA1584), and Department of Food, Agricultural and Biological Engineering (FABE), The Ohio State University (OSU). 


\section{References}

1. Avci, A., Saha, B.C., Kennedy, G.J., Cotta, M. A., 2013. Dilute sulfuric acid pretreatment of corn stover for enzymatic hydrolysis and efficient ethanol production by recombinant Escherichia coli FBR5 without detoxification. Bioresour. Technol. 142, 312-319.

2. Bals, B.D., Gunawan, C., Moore, J., Teymouri, F., Dale, B.E., 2014. Enzymatic hydrolysis of pelletized $\mathrm{AFEX}^{\mathrm{TM}}$-treated corn stover at high solid loadings. Biotechnol. Bioeng. 111, 264-271.

3. Baral, N.R., Shah, A., 2015. Techno-economic analysis of cellulose dissolving ionic liquid pretreatment of lignocellulosic biomass for fermentable sugars production. Biofuels, Bioprod. Biorefining 6, 246-256.

4. Baral, N.R., Shah, A., 2014. Microbial inhibitors: formation and effects on acetonebutanol-ethanol fermentation of lignocellulosic biomass. Appl. Microbiol. Biotechnol. 98, 9151-9172.

5. Bondesson, P.M., Galbe, M., Zacchi, G., 2013. Ethanol and biogas production after steam pretreatment of corn stover with or without the addition of sulphuric acid. Biotechnol. Biofuels 6, 11.

6. Brown, R.C., 2003. Biorenewable Resources:Engineering New Products from Agriculture. Backwell Publishing, Iowa, pp.229-263.

7. Cheng, J., 2010. Biological process for ethanol production. In Biomass to renewable energy processes (pp.209-270). CRC Press.

8. Department of Energy, National Energy Technology Laboratory (DOE/NETL), 2002. Process equipment cost estimation - Final report. http://www.chemeng.lth.se/ket050/Arkiv/KostnadsDataProcessutrustning2002.pdf [Accessed September 20, 2015].

9. DOE. U.S., 2011. Billion-Ton Update, U.S. Department of Energy. Retrieved from http://www1.eere.energy.gov/bioenergy/pdfs/billion_ton_update.pdf [Accessed September 11, 2015]

10. Eggeman, T., Elander, R.T., 2005. Process and economic analysis of pretreatment technologies. Bioresour. Technol. 96, 2019-2025.

11. Energy Information Administration (EIA), 2014. Average Price of Electricity to Ultimate Customers by End-Use Sector. U.S. Energy Information Administration. https://www.eia.gov/electricity/monthly/epm_table_grapher.cfm?t=epmt_5_6_a [Accessed November 08, 2015].

12. Ezeji, T.C., Qureshi, N., Blaschek, H.P., 2003. Production of acetone, butanol and ethanol by Clostridium beijerinckii BA101 and in situ recovery by gas stripping. World J. Microbiol. Biotechnol. 19, 595-603.

13. Gao, Z., Mori, T., Kondo, R., 2012. The pretreatment of corn stover with Gloeophyllum trabeum KU-41 for enzymatic hydrolysis. Biotechnol. Biofuels 5, 28.

14. Intelligen, Inc., 2014. SuperPro Designer-User's Guide, Scotch Plains, New Jersey.

15. Jurgens, G., Survase, S., Berezina, O., Sklavounos, E., Linnekoski, J., Kurkijärvi, A., 
Väkevä, M., van Heiningen, A., Granström, T., 2012. Butanol production from lignocellulosics. Biotechnol. Lett. 34, 1415-1434.

16. Kazi, F.K., Fortman, J.A., Anex, R.P., Hsu, D.D., Aden, A., Dutta, A. and Kothandaraman, G., 2010. Techno-economic comparison of process technologies for biochemical ethanol production from corn stover. Fuel 89, S20-S28.

17. Keller, F., Hamilton, J., Nguyen, Q., 2003. Microbial pretreatment of biomass. Appl. Biochem. Biotechnol. 105-108, 27-41.

18. Kim, S., Holtzapple, M.T., 2005. Lime pretreatment and enzymatic hydrolysis of corn stover. Bioresour. Technol. 96, 1994-2006.

19. Kim, T.H., Kim, J.S., Sunwoo, C., Lee, Y.Y., 2003. Pretreatment of corn stover by aqueous ammonia. Bioresour. Technol. 90, 39-47.

20. Klein-Marcuschamer, D., Simmons, B.A. and Blanch, H.W., 2011. Techno-economic analysis of a lignocellulosic ethanol biorefinery with ionic liquid pre-treatment. Biofuels, Bioproducts and Biorefining 5(5), 562-569.

21. Kumar, D., Murthy, G.S., 2011. Impact of pretreatment and downstream processing technologies on economics and energy use in cellulosic ethanol production. Biotechnol. Biofuels 4, 27.

22. Kumar, P., Barrett, D.M., Delwiche, M.J., Stroeve, P., 2009. Methods for Pretreatment of Lignocellulosic Biomass for Efficient Hydrolysis and Biofuel Production. Ind. Eng. Chem. Res. 48, 3713-3729.

23. Lau, M.W., Gunawan, C., Dale, B.E., 2009. The impacts of pretreatment on the fermentability of pretreated lignocellulosic biomass: a comparative evaluation between ammonia fiber expansion and dilute acid pretreatment. Biotechnol. Biofuels 2, 30.

24. Li, C., Cheng, G., Balan, V., Kent, M.S., Ong, M., Chundawat, S.P.S., Sousa, L. daCosta, Melnichenko, Y.B., Dale, B.E., Simmons, B. a., Singh, S., 2011. Influence of physicochemical changes on enzymatic digestibility of ionic liquid and AFEX pretreated corn stover. Bioresour. Technol. 102, 6928-6936.

25. Liu, S., Wu, S., Pang, C., Li, W., Dong, R., 2014. Microbial pretreatment of corn stovers by solid-state cultivation of Phanerochaete chrysosporium for biogas production. Appl. Biochem. Biotechnol. 172, 1365-1376.

26. Liu, Z.H., Qin, L., Pang, F., Jin, M.J., Li, B.Z., Kang, Y., Dale, B.E., Yuan, Y.J., $2013 b$. Effects of biomass particle size on steam explosion pretreatment performance for improving the enzyme digestibility of corn stover. Ind. Crops Prod. 44, 176-184.

27. Lloyd, T. A., Wyman, C.E., 2005. Combined sugar yields for dilute sulfuric acid pretreatment of corn stover followed by enzymatic hydrolysis of the remaining solids. Bioresour. Technol. 96, 1967-1977.

28. Ma, K., Ruan, Z., 2015. Production of a lignocellulolytic enzyme system for simultaneous bio-delignification and saccharification of corn stover employing co-culture of fungi. Bioresour. Technol. 175, 586-593.

29. Mariano, A.P., Qureshi, N., Maciel Filho, R., Ezeji, T.C., 2012. Assessment of in situ 
butanol recovery by vacuum during acetone butanol ethanol (ABE) fermentation. J. Chem. Technol. Biotechnol. 87, 334-340.

30. Mood, S., Hossein Golfeshan, A., Tabatabaei, M., Salehi Jouzani, G., Najafi, G.H., Gholami, M., Ardjmand, M., 2013. Lignocellulosic biomass to bioethanol, a comprehensive review with a focus on pretreatment. Renew. Sustain. Energy Rev. 27, 77-93.

31. National Renewable Energy Laboratory (NREL), 2015. Process Design and Economics for the Conversion of Lignocellulosic Biomass to Hydrocarbons:Dilute-Acid and Enzymatic Deconstruction of Biomass to Sugars and Catalytic Conversion of Sugars to Hydrocarbons. Retrieved from : http://www.nrel.gov/docs/fy15osti/62498.pdf [Accessed June 02, 2016].

32. National Renewable Energy Laboratory (NREL), 2011. Process Design and Economics for Biochemical Conversion of Lignocellulosic Biomass to Ethanol Process Design and Economics for Biochemical Conversion of Lignocellulosic Biomass to Ethanol National Renewable Energy Laboratory. Retrieved from http://www.nrel.gov/biomass/pdfs/51400.pdf4 [Accessed September 02, 2015]

33. National Renewable Energy Laboratory (NREL), 2002. Lignocellulosic Biomass to Ethanol Process Design and Economics Utilizing Co-Current Dilute Acid Prehydrolysis and Enzymatic Hydrolysis for Corn Stover. National Renewable Energy Laboratory. Retrieved from http://www.nrel.gov/docs/fy02osti/32438.pdf [Accessed September 04, 2015].

34. Oleskowicz-Popiel, P., Klein-Marcuschamer, D., Simmons, B. a., Blanch, H.W., 2014. Lignocellulosic ethanol production without enzymes - Technoeconomic analysis of ionic liquid pretreatment followed by acidolysis. Bioresour. Technol. 158, 294-299.

35. Qin, L., Liu, Z.H., Li, B.Z., Dale, B.E., Yuan, Y.J., 2012. Mass balance and transformation of corn stover by pretreatment with different dilute organic acids. Bioresour. Technol. 112, 319-326.

36. Qureshi, N., Saha, B.C., Hector, R.E., Cotta, M. A., 2008. Removal of fermentation inhibitors from alkaline peroxide pretreated and enzymatically hydrolyzed wheat straw: Production of butanol from hydrolysate using Clostridium beijerinckii in batch reactors. Biomass and Bioenergy 32, 1353-1358.

37. Qureshi, N., Saha, B.C., Hector, R.E., Dien, B., Hughes, S., Liu, S., Iten, L., Bowman, M.J., Sarath, G., Cotta, M. A., 2010. Production of butanol (a biofuel) from agricultural residues: Part II - Use of corn stover and switchgrass hydrolysates. Biomass and Bioenergy 34, 566-571.

38. Shah, A., Darr, M., 2016. A techno-economic analysis of the corn stover feedstock supply system for cellulosic biorefineries. Biofuels Bioprod. Biorefin.

39. Shen, J., Wyman, C.E., 2011. A novel mechanism and kinetic model to explain enhanced xylose yields from dilute sulfuric acid compared to hydrothermal pretreatment of corn stover. Bioresour. Technol. 102, 9111-9120. 
40. Sindhu, R., Binod, P., Pandey, A., 2015. Biological pretreatment of lignocellulosic biomass - an overview. Bioresour. Technol. 199, 76-82.

41. Song, L., Ma, F., Zeng, Y., Zhang, X., Yu, H., 2013. The promoting effects of manganese on biological pretreatment with Irpex lacteus and enzymatic hydrolysis of corn stover. Bioresour. Technol. 135, 89-92.

42. Tao, L., He, X., Tan, E.C.D., Zhang, M., Aden, A., 2014. Comparative techno-economic analysis and reviews of n-butanol production from corn grain and corn stover. Biofuels, Bioprod. Biorefining 8, 342-361.

43. Ulrich, G., 1984. A Guide to Chemical Engineering Process Design and Economics. John Willy \& Sons Inc., New York, pp. 265-323.

44. Uppugundla, N., da Costa Sousa, L., Chundawat, S.P., Yu, X., Simmons, B., Singh, S., Gao, X., Kumar, R., Wyman, C.E., Dale, B.E., Balan, V., 2014. A comparative study of ethanol production using dilute acid, ionic liquid and $\mathrm{AFEX}^{\mathrm{TM}}$ pretreated corn stover. Biotechnol. Biofuels 7, 72.

45. Varga, E., Réczey, K., Zacchi, G., 2004. Optimization of steam pretreatment of corn stover to enhance enzymatic digestibility. Appl. Biochem. Biotechnol. 113-116, 509-523.

46. Wan, C., Li, Y., 2010. Microbial pretreatment of corn stover with Ceriporiopsis subvermispora for enzymatic hydrolysis and ethanol production. Bioresour. Technol. $101,6398-403$.

47. Wang, F.Q., Xie, H., Chen, W., Wang, E.T., Du, F.G., Song, A.D., 2013. Biological pretreatment of corn stover with ligninolytic enzyme for high efficient enzymatic hydrolysis. Bioresour. Technol. 144, 572-578.

48. Wyman, C.E., Dale, B.E., Elander, R.T., Holtzapple, M., Ladisch, M.R., Lee, Y.Y., 2005. Comparative sugar recovery data from laboratory scale application of leading pretreatment technologies to corn stover. Bioresour. Technol. 96, 2026-2032.

49. Xu, C., Ma, F., Zhang, X., Chen, S., 2010. Biological pretreatment of corn stover by Irpex lacteus for enzymatic hydrolysis. J. Agric. Food Chem. 58, 10893-8.

50. Zimbardi, F., Viola, E., Nanna, F., Larocca, E., Cardinale, M., Barisano, D., 2007. Acid impregnation and steam explosion of corn stover in batch processes. Ind. Crops Prod. 26, 195-206. 


\section{List of Tables}

Table 1. Structural composition (wt\%) of corn stover

\begin{tabular}{lllllll}
\hline Cellulose & Hemicellulose & Lignin & Ash & Acetate & Others* & References \\
\hline 40.19 & 29.2 & 20.83 & 7.08 & 2.2 & 0.5 & Kim et al., 2003 \\
36.1 & 31.3 & 17.2 & 7.1 & 3.2 & 5.1 & Varga et al., 2004 \\
36.1 & 22.6 & 20.8 & 6.9 & - & 13.6 & Kim and Holtzapple, 2005 \\
33.6 & 26.2 & 14.1 & 2.6 & - & 23.5 & Bondesson et al., 2013 \\
33.4 & 21.4 & 17.2 & 3.6 & 2.1 & 22.3 & Uppugundla et al., 2014 \\
36.1 & 21.4 & 13.6 & 2.8 & - & 26.1 & Shen and Wyman, 2011 \\
35.05 & 23.94 & 15.76 & 4.93 & 1.81 & 18.51 & NREL, 2011 \\
$\mathbf{3 5 . 9 2}$ & $\mathbf{2 5 . 3 5}$ & $\mathbf{1 7 . 2 9}$ & $\mathbf{5 . 0 1}$ & $\mathbf{2 . 3 3}$ & $\mathbf{1 5 . 1 8}$ & $\begin{array}{l}\text { Average value } \\
\text { (used in this study) }\end{array}$ \\
\hline
\end{tabular}

* Others components were estimated by difference to get $100 \%$ material balance. These components include free glucose, free xylose, water and ethanol extractive used as an extractive in the process model. 
Table 2. Capital investment for different pretreatment processes to produce 113.5 million liters butanol per year

\begin{tabular}{lcccc}
\hline \multirow{2}{*}{ Parameters } & \multicolumn{4}{c}{ Capital Investment (million dollars) } \\
\cline { 2 - 5 } & Steam explosion & Sulfuric acid & AFEX & Biological \\
\hline Total fixed capital & 119 & 108 & 82 & 1415 \\
Working capital & 12 & 11 & 21 & 22 \\
Startup cost & 6 & 6 & 4 & 71 \\
Total & $\mathbf{1 3 7}$ & $\mathbf{1 2 5}$ & $\mathbf{1 0 7}$ & $\mathbf{1 5 0 8}$ \\
\hline
\end{tabular}


Table 3. Annual operating cost for different pretreatment processes to produce 113.5 million liters butanol per year

\begin{tabular}{lcccc}
\hline \multirow{2}{*}{ Parameters } & \multicolumn{4}{c}{ Annual operating cost (million dollars) } \\
\cline { 2 - 5 } & Steam explosion & Sulfuric acid & AFEX & Biological \\
\hline Corn stover & 91 & 82 & 74 & 199 \\
Other materials & 23 & 23 & 31 & 50 \\
Labor-dependent & 4 & 4 & 4 & 4 \\
Facility-dependent & 23 & 22 & 15 & 290 \\
Utilities & 12 & 14 & 116 & 4 \\
Total & $\mathbf{1 5 3}$ & $\mathbf{1 4 5}$ & $\mathbf{2 4 0}$ & $\mathbf{5 4 7}$ \\
\hline
\end{tabular}


Table 4. Comparison of sugar production cost from previous studies

\begin{tabular}{|c|c|c|c|c|c|}
\hline \multirow{2}{*}{ Techno-economic study } & \multirow{2}{*}{$\begin{array}{c}\text { Biomass } \\
\text { feedstock } \\
\text { cost }(\$ / t)\end{array}$} & \multicolumn{4}{|c|}{ Sugar production cost $(\$ / \mathrm{kg})$} \\
\hline & & Steam explosion & Sulfuric acid & AFEX & Biological \\
\hline This study & 110.5 & 0.43 & 0.42 & 0.65 & 1.41 \\
\hline NREL, 2011 & 64.5 & - & 0.26 & - & - \\
\hline NREL, 2002 & 38.6 & - & 0.14 & - & - \\
\hline Kazi et al., 2010 & 83 & - & $0.24 *$ & $0.23 *$ & - \\
\hline Kumar and Murthy, 2011 & 50 & $0.23 *$ & $0.22 *$ & - & \\
\hline Eggeman and Elander, 2005 & 38.6 & - & $0.09 *$ & $0.1 *$ & \\
\hline
\end{tabular}




\section{Figure Captions}

Figure 1. Overview of pretreatment process with some major process equipment

Figure 2. Conversion of glucan, xylan and lignin with severity factor during different pretreatment process

(In ordinate, 'Yield' refers to glucose, xylose and soluble lignin yield as well as 'Losses' refer to glucan, xylan and lignin losses. This figure summarizes experimental data on glucan $(\diamond)$, xylan $(\square)$ and lignin $(\Delta)$ conversions under different pretreatment processes, including steam explosion pretreatment (A1, A2 and A3, respectively for glucan, xylan and lignin); dilute sulfuric acid pretreatment (B1, B2 and B3, respectively for glucan, xylan and lignin); AFEX pretreatment (C); and biological pretreatment (D). In addition, data used by recent techno-economic studies are also included (×Eggeman and Elander, 2005; • Kazi et al., 2010 and $\mathbf{\Delta}$ NREL, 2011).

Figure 3. Conversion of cellulose and hemicellulose into glucose and xylose during enzymatic hydrolysis of pretreated corn stover

(In ordinate, 'Yield' refers to glucose and xylose yields. This figure summarizes experimental data on glucan $(\Delta)$ and xylan $(\diamond)$ conversions during enzymatic hydrolysis following the different pretreatment processes, including Steam explosion pretreatment (A1 and A2, respectively for glucose and xylose); dilute sulfuric acid pretreatment (B1 and B2, respectively for glucose and xylose); AFEX pretreatment (C); and biological pretreatment (D). In addition, data used by recent techno-economic studies during enzymatic hydrolysis process of pretreated corn stover under different pretreatment process are also included (×Eggeman and Elander, 2005; •Kazi et al., 2010 and $\boldsymbol{\Delta}$ NREL, 2011).) 
Figure 4. Material and energy requirement to produce $1 \mathrm{t}$ total sugars under different pretreatment methods (First, second, third and fourth values in this figure refer to steam explosion, sulfuric acid, AFEX and biological pretreatment, respectively).

Figure 5. Fermentable sugar production cost under different pretreatment processes

Figure 6. Sensitivity analysis of different pretreatment processes: steam explosion (A), sulfuric acid (B), AFEX (C) and biological (D). 


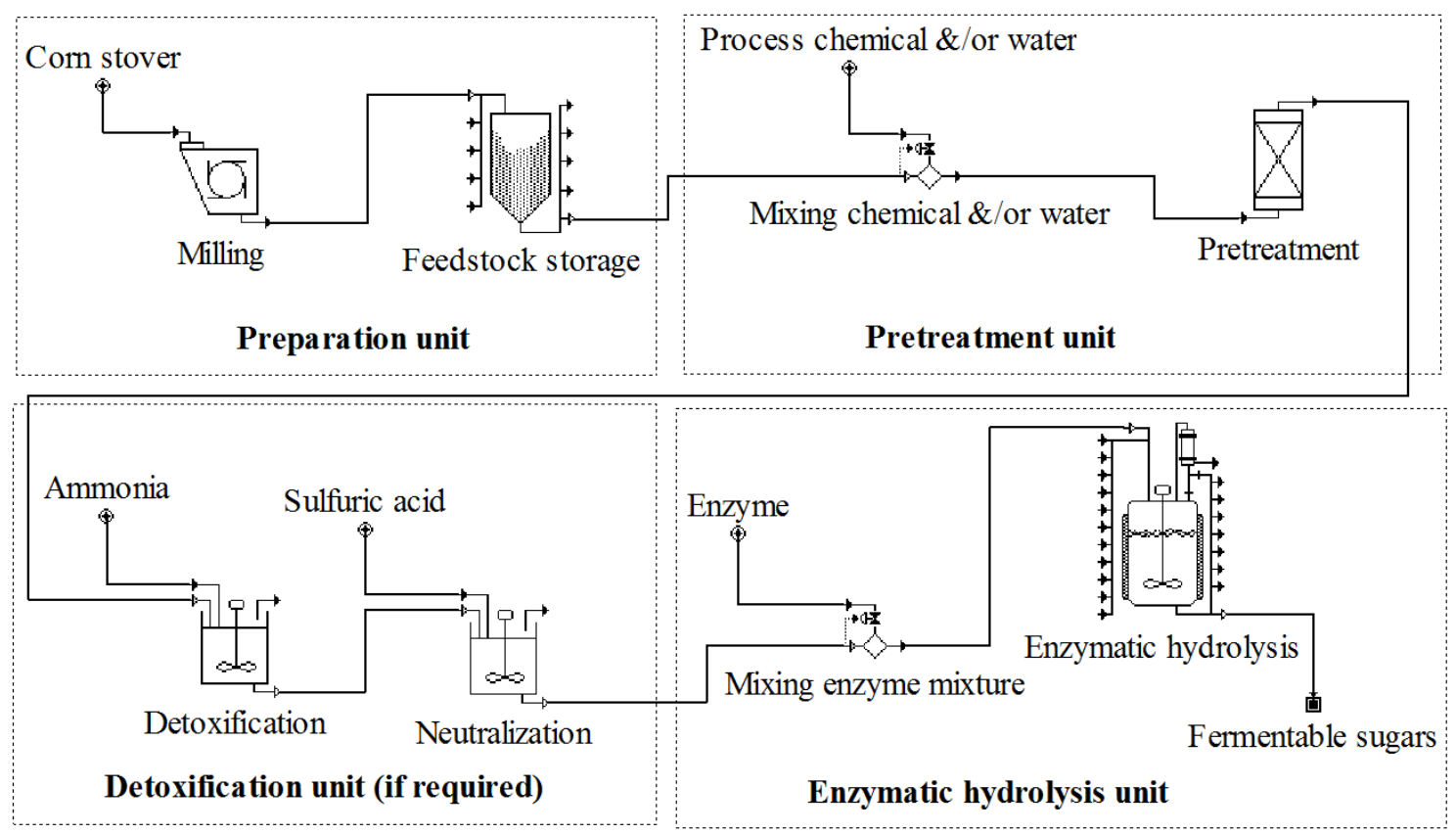

Figure 1. Overview of pretreatment process with some major process equipment 

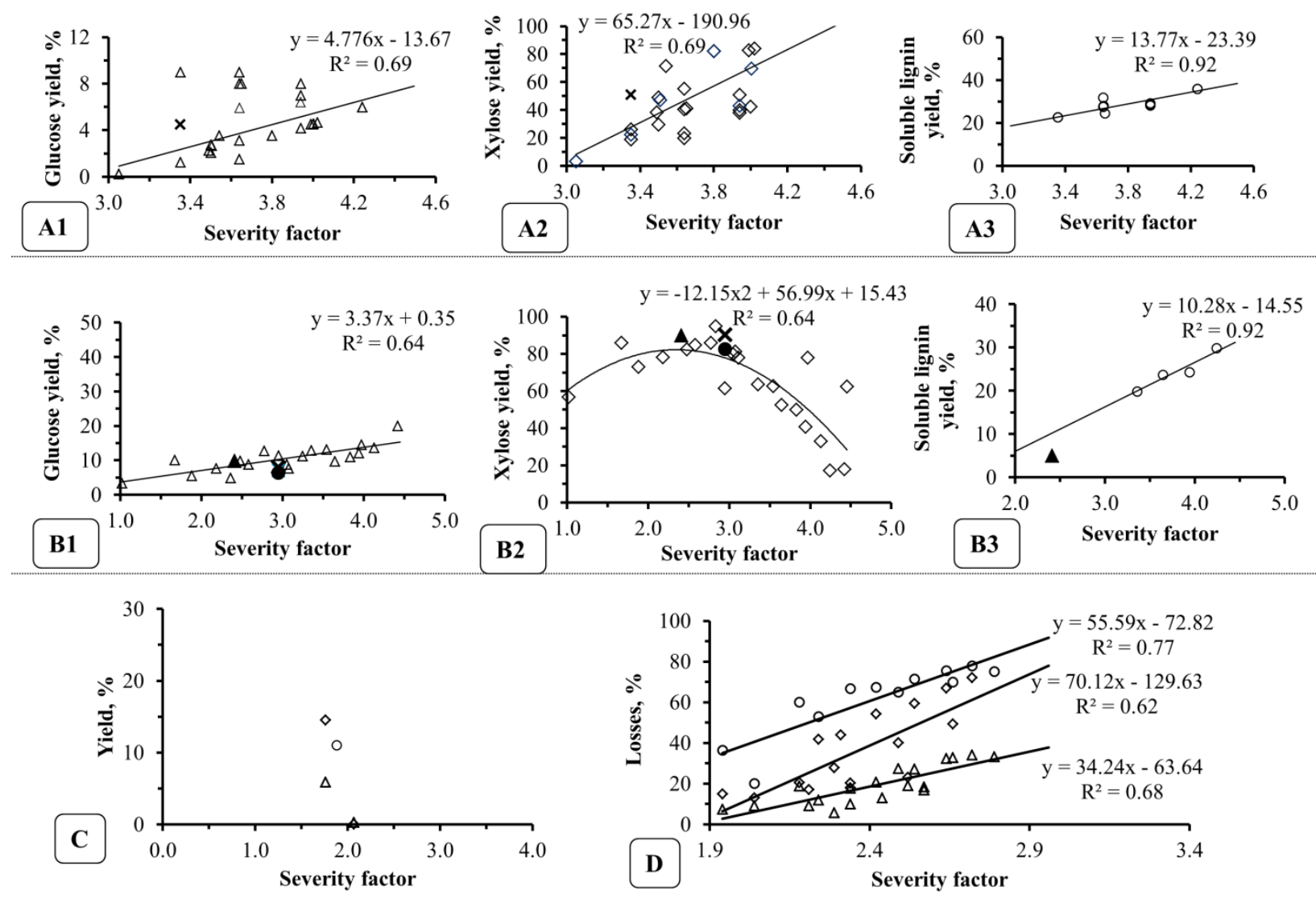

Figure 2. Conversion of glucan, xylan and lignin with severity factor during different pretreatment process

(In ordinate, 'Yield' refers to glucose, xylose and soluble lignin yield as well as 'Losses' refer to glucan, xylan and lignin losses. This figure summarizes experimental data on glucan $(\diamond)$, xylan (口) and lignin $(\Delta)$ conversions under different pretreatment processes, including steam explosion pretreatment (A1, A2 and A3, respectively for glucan, xylan and lignin); dilute sulfuric acid pretreatment (B1, B2 and B3, respectively for glucan, xylan and lignin); AFEX pretreatment (C); and biological pretreatment (D). In addition, data used by recent techno-economic studies are also included (×Eggeman and Elander, 2005; •Kazi et al., 2010 and $\mathbf{\Delta}$ NREL, 2011). 

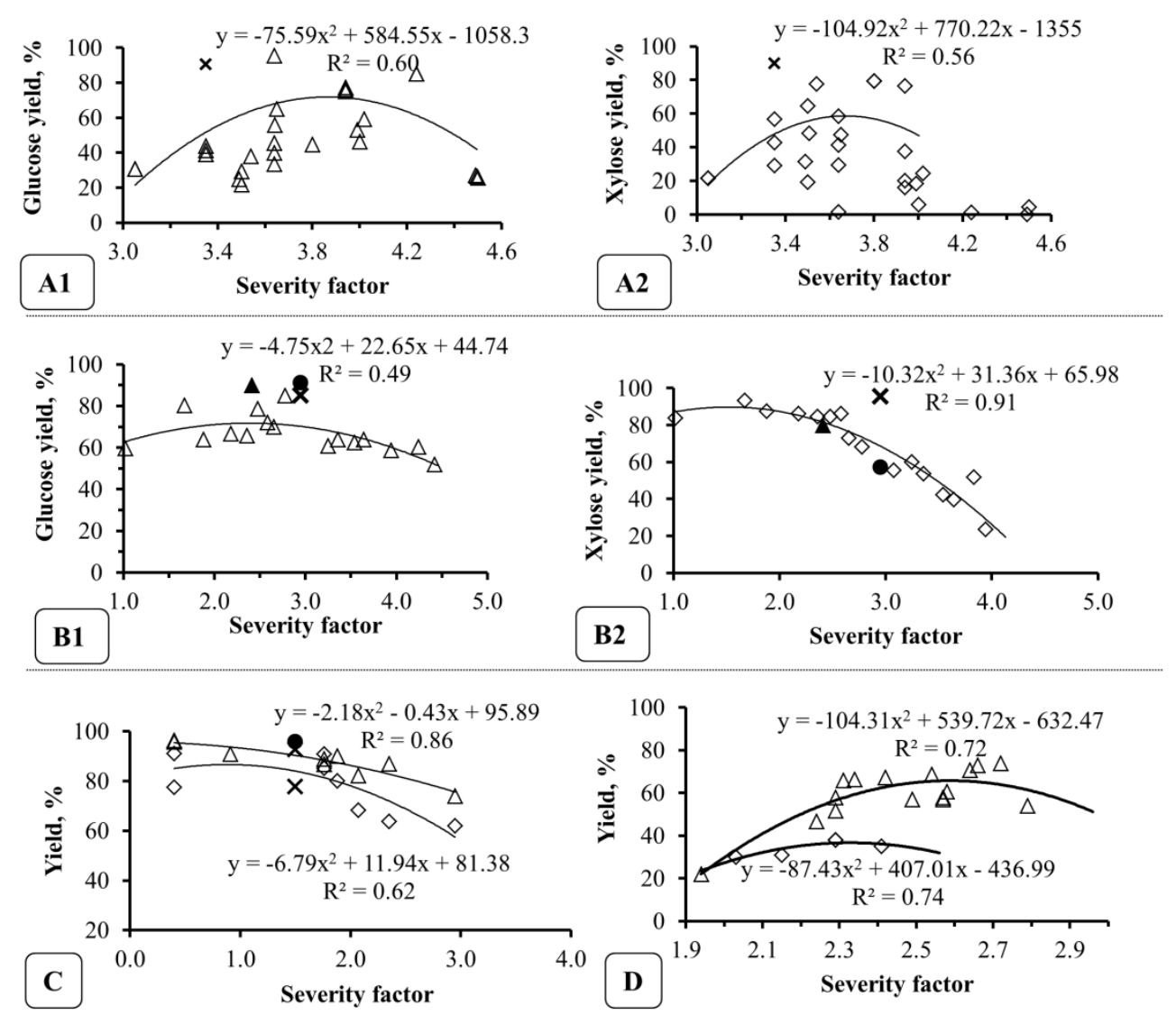

Figure 3. Conversion of cellulose and hemicellulose into glucose and xylose during enzymatic hydrolysis of pretreated corn stover

(In ordinate, 'Yield' refers to glucose and xylose yields. This figure summarizes experimental data on glucan $(\Delta)$ and xylan $(\diamond)$ conversions during enzymatic hydrolysis following the different pretreatment processes, including Steam explosion pretreatment (A1 and A2, respectively for glucose and xylose); dilute sulfuric acid pretreatment (B1 and B2, respectively for glucose and xylose); AFEX pretreatment (C); and biological pretreatment (D). In addition, data used by recent techno-economic studies during enzymatic hydrolysis process of pretreated corn stover under different pretreatment process are also included (×Eggeman and Elander, 2005; •Kazi et al., 2010 and $\mathbf{\Delta}$ NREL, 2011).) 


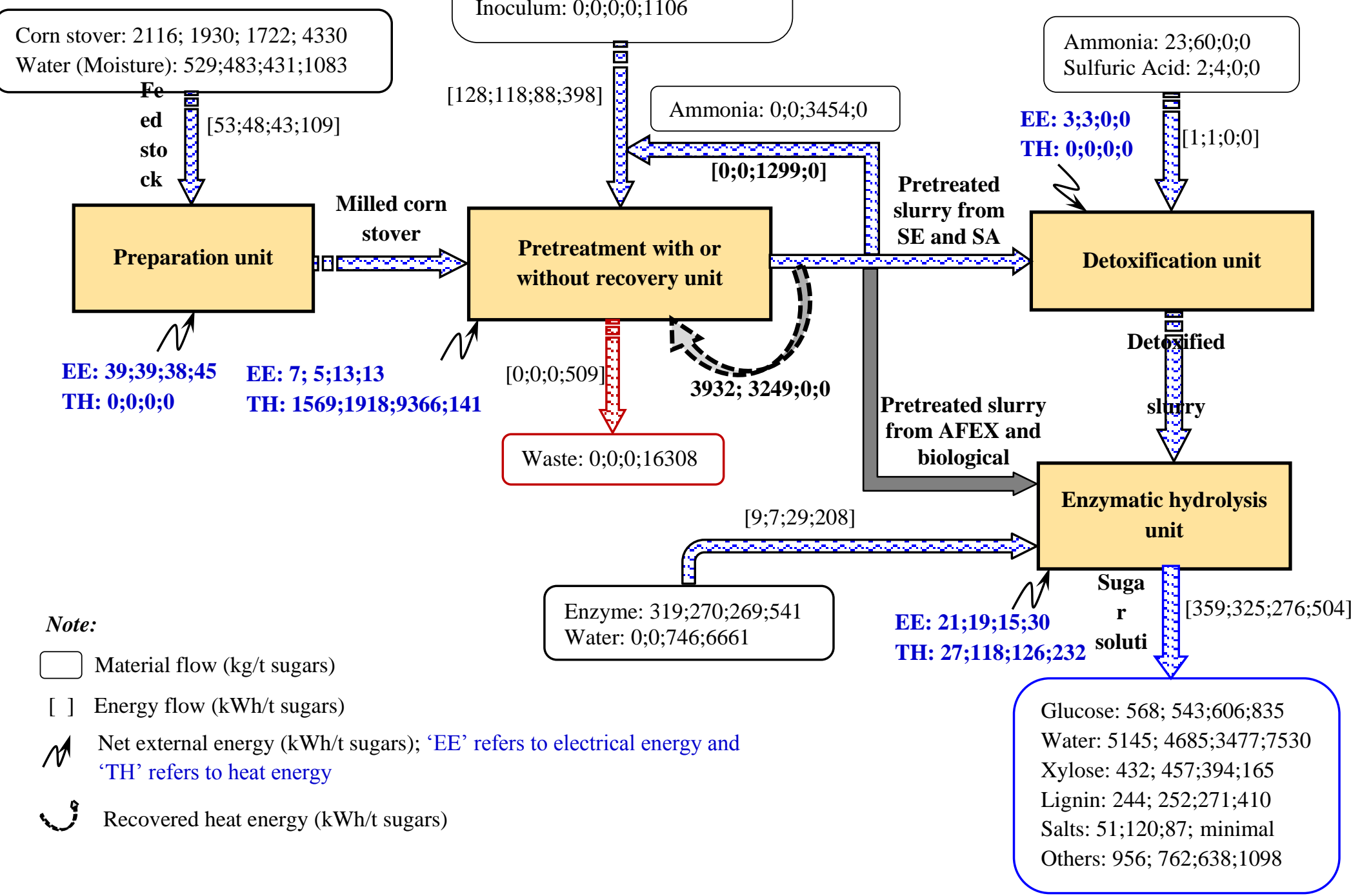

Figure 4. Material and energy requirement to produce $1 \mathrm{t}$ total sugars under different pretreatment methods (First, second, third and fourth values in this figure refer to steam explosion, sulfuric acid, AFEX and biological pretreatment, respectively). 


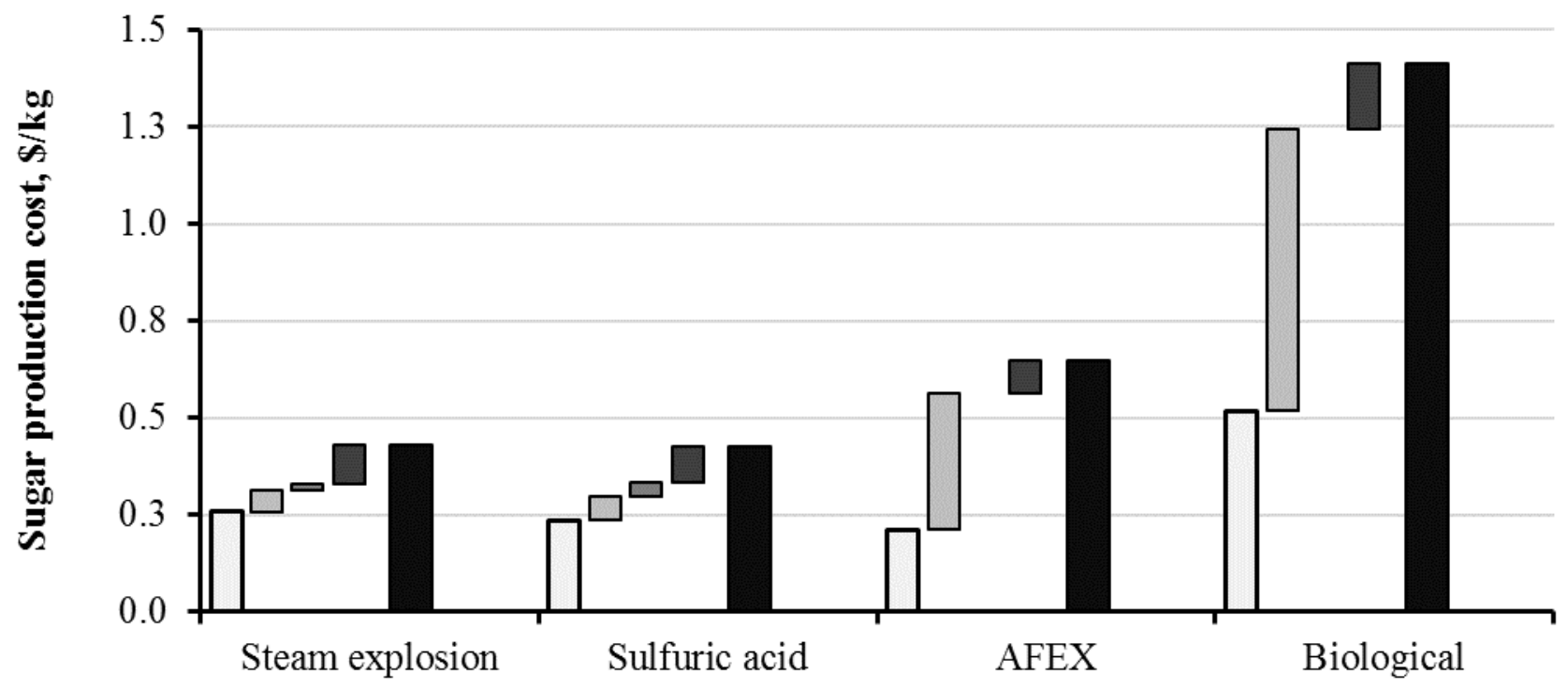

$\square$ Feedstock preparation $\square$ Pretreatment $\square$ Detoxification $\square$ Enzymatic hydrolysis $\boldsymbol{\square}$ Total cost

Figure 5. Fermentable sugar production cost under different pretreatment processes 


Feedstock cost
Glucose yield (ENZ)
Heat recovery
Severity factor
Xylose yield (PRT)
Enzyme cost
Xylose yield (ENZ)
Solid loading rate
Glucose yield (PRT)
Plant size

Sugar loss during detoxification

Moisture content

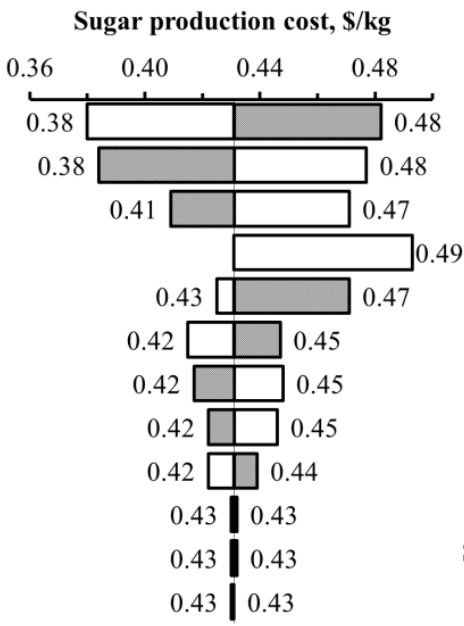

Sugar production cost, $\$ / \mathbf{k g}$

$\begin{array}{llll}0.54 & 0.62 & 0.70 & 0.78\end{array}$

Solid loading rate

Glucose yield (ENZ)

Xylose yield (ENZ)

Feedstock cost

Severity factor

Plant size

Enzyme cost

Moisture content

\section{B}

Feedstock cost

Glucose yield (ENZ)

Heat recovery

Severity factor

Solid loading rate

Enzyme cost

Xylose yield (ENZ)

Xylose yield (PRT)

Plant size

Moisture content

Sugar loss during detoxification

Glucose yield (PRT)

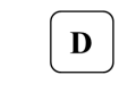

Glucose yield (ENZ)

Solid loading rate

Severity factor

Feedstock cost

Xylan loss (PRT)

Xylose yield (ENZ)

Glucan loss (PRT)

Enzyme cost

Plant size

Moisture content
Sugar production cost, $\$ / \mathbf{k g}$

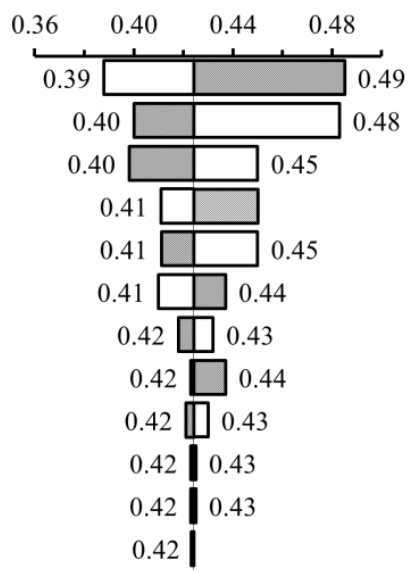

Sugar production cost, $\$ / \mathbf{k g}$

\begin{tabular}{|c|c|c|c|}
\hline 1.30 & 1.50 & 1.7 & \\
\hline 1.21 & & & 1.70 \\
\hline 1.29[ & & 1.58 & \\
\hline 1.31 & & 1.58 & \\
\hline 1.31[ & & & \\
\hline 1.35 & $\mid$\begin{tabular}{|l}
1.4 \\
|
\end{tabular} & & \\
\hline 1.37 & 1.46 & & \\
\hline 1.37 & 1.46 & & \\
\hline 1.3 & 1.44 & & \\
\hline 1. & 1.42 & & \\
\hline & 1.42 & & \\
\hline
\end{tabular}

Figure 6. Sensitivity analysis of different pretreatment processes: steam explosion (A), sulfuric acid (B), AFEX (C) and biological (D).

51. 